\title{
Racial/ethnic disparities in survival of metastatic prostate cancer patients treated with external beam radiotherapy
}

\author{
Wenxiao $\mathrm{Yu}^{1} \cdot$ Jun Guo ${ }^{1}$
}

Received: 5 October 2021 / Accepted: 5 October 2021 / Published online: 18 October 2021

(c) The Author(s), under exclusive licence to Springer-Verlag GmbH Germany, part of Springer Nature 2021

\section{Dear Editor}

We read the study by Würnschimmel et al. [1] with great interest and would like to congratulate the authors for their superb study. The authors assessed the effect of race/ethnicity in cancer-specific mortality adjusted for other-cause mortality in metastatic prostate cancer patients (mPCa) treated with external beam radiotherapy to the prostate.

1. The factors extracted by the researchers from the SEER database (2004-2016) include clinical T stage and clinical N stage. However, according to the SEER Program [2], the "clinical stage" variable was not provided in the dataset until 2016. Therefore, for patients diagnosed before 2016, it was impossible for authors to identify the clinical stage. How to obtain the clinical stage of patients diagnosed between 2004 and 2016 needs to be explained in detail.

2. Some of the patients included in the analysis received chemotherapy. This type of treatment should be taken into consideration since prior literature showed that chemotherapy holds great potential in the management of mPCa patients [3, 4].

3. Patients diagnosed with primary $\mathrm{mPCa}$ were included in this study, but multiple primary cancers were not excluded. However, another SEER-based study showed $\mathrm{mPCa}$ patients were at a significantly higher risk of developing a second malignancy, which may affect patients' survival [5].

This comment refers to the article available online at https://doi. org/10.1007/s00345-021-03720-7.

Jun Guo

guojun1126@126.com

1 Department of Andrology, Xiyuan Hospital, China Academy of Chinese Medical Sciences, Beijing 100091, China
Author contribution WY: reviewed the relevant study and drafted this letter. JG: revised this letter for critical content and scientific rigour.

Funding None.

Availability of data and materials Not applicable.

Code availability Not applicable.

\section{Declarations}

Conflict of interest The authors declare that they have no conflict of interest.

Research involving human participants and/or animals Not applicable.

Informed consent Not applicable.

\section{References}

1. Würnschimmel C, Wenzel M, Collà Ruvolo C, Nocera L, Tian Z, Saad F, Briganti A, Shariat SF, Mandel P, Chun FKH, Tilki D, Graefen M, Karakiewicz PI (2021) Survival advantage of Asian metastatic prostate cancer patients treated with external beam radiotherapy over other races/ethnicities. World J Urol. https:// doi.org/10.1007/s00345-021-03720-7

2. Ruhl J, Adamo M, Dickie L (2016) SEER program coding and staging manual 2016: section V. National Cancer Institute, Bethesda, MD, pp 20850-29765

3. Quinn DI, Sandler HM, Horvath LG, Goldkorn A, Eastham JA (2017) The evolution of chemotherapy for the treatment of prostate cancer. Ann Oncol 28(11):2658-2669. https://doi.org/10. 1093/annonc/mdx348

4. Saad F (2015) Prostate cancer in 2014: the year chemotherapy finally gets some respect! Nat Rev Urol 12(2):71-72. https://doi. org/10.1038/nrurol.2014.362

5. Davis EJ, Beebe-Dimmer JL, Yee CL, Cooney KA (2014) Risk of second primary tumors in men diagnosed with prostate cancer: a population-based cohort study. Cancer 120(17):2735-2741. https://doi.org/10.1002/cncr.28769

Publisher's Note Springer Nature remains neutral with regard to jurisdictional claims in published maps and institutional affiliations. 